\title{
CLOTTING AND FIBRINOLYTIC DISTURBANCE DURING LUNG TRANSPLANTATION: EFFECT OF LOW-DOSE APROTININ
}

Y. J. Gu, MD, PhD

J. de Haan, $\mathrm{PhD}$

U. P. M. Brenken, MD, PhD

W. J. de Boer, MD

$\mathrm{Jm}$. Prop, $\mathrm{MD}, \mathrm{PhD}$

W. van Oeveren, $\mathrm{PhD}$

Groningen Lung Transplant Group
Patients undergoing lung transplantation are often confronted with a bleeding problem that may be due in part to the use of cardiopulmonary bypass and its activation of blood clotting and fibrinolysis. Objective: We performed a prospective study to determine whether and to what extent the clotting and fibrinolytic systems are being activated and whether low-dose aprotinin is effective in inhibiting blood activation during lung transplantation. Methods: Thirty lung transplantations performed on 29 patients were divided into a group with cardiopulmonary bypass alone $(n=12)$, a group with cardiopulmonary bypass and $2 \times 10^{6} \mathrm{KIU}$ aprotinin administered at the beginning of bypass in the pump prime $(n=12)$, and a group without cardiopulmonary bypass $(n=6)$. Serial blood samples were taken from the recipient before anesthesia, seven times during the operation, and 4 and 24 hours thereafter. Results: Results show that in the group having cardiopulmonary bypass alone, the concentration of the clotting marker thrombin/antithrombin III complex increased significantly during the early phase of the operation $(p<0.01)$ and remained high until the end of the operation. Levels of tissue-type plasminogen activator, a trigger of fibrinolysis released by injured endothelium, also increased sharply in the early phase of the operation in the cardiopulmonary bypass group $(p<0.01)$, followed by a significant increase in fibrin degradation products $(p<0.01)$. In the aprotinin group, a significant reduction of thrombin/antithrombin III complex $(p<0.05)$, tissue-type plasminogen activator $(p<0.05)$, and fibrin degradation products $(p<0.05)$ was observed in the early phase of the operation compared with levels in the bypass group, but these markers increased late during bypass associated with a significant drop $(p<0.05)$ of plasma aprotinin level monitored by plasmin inhibiting capacity. In the nonbypass group, concentrations of thrombin/antithrombin III complex and tissue-type plasminogen activator also rose significantly $(p<0.05)$ in the early phase of the operation, but the levels were significantly lower than those of the bypass group $(p<0.05)$. Blood loss during the operation was $2521 \pm 550$ $\mathrm{ml}$ in the bypass group, $1991 \pm 408 \mathrm{ml}$ in the aprotinin/bypass group, and 875 $\pm 248 \mathrm{ml}$ in the nonbypass group. Conclusion: These results suggest that clotting and fibrinolysis are activated during lung transplantation, especially in patients undergoing cardiopulmonary bypass. Aprotinin in a low dose significantly reduced activation of clotting and fibrinolysis in the early phase of the operation but not during the late phase of lung transplantation. ( $J$ Thorac Cardiovasc Surg 1996;112:599-606)
From University Hospital Groningen, Groningen, The Netherlands.

Received for publication Dec. 13, 1995; revisions requested Feb. 13, 1996; revisions received March 14, 1996; accepted for publication March 19, 1996.

Address for reprints: W. van Oeveren, $\mathrm{PhD}$, Blood Interaction Research, Department of Cardiothoracic Surgery, University Hospital Groningen, 59 Oostersingel, 9713 EZ Groningen, The Netherlands.

Copyright (C) 1996 by Mosby-Year Book, Inc.

0022-5223/96 $\$ 5.00+0 \quad \mathbf{1 2 / 1 / 7 3 5 2 9}$
Datients undergoing lung transplantation are often confronted with excessive intraoperative bleeding followed by large amounts of transfused blood. ${ }^{1-3}$ To a large extent, this problem is attributed to the underlying lung diseases, which require extensive surgical manipulation of the chest wall during the operation. ${ }^{2}$ Furthermore, cardiopulmonary bypass $(\mathrm{CPB})$ is frequently used during lung transplantation to support the recipient's hemodynamic stability. ${ }^{4,5}$ However, the use of CPB may aggravate 
Table I. Patients demographic data (mean \pm standard deviation)

\begin{tabular}{lccc}
\hline \multicolumn{1}{c}{ Parameter } & $\begin{array}{c}C P B \\
(n=12)\end{array}$ & $\begin{array}{c}\text { CPB/aprotinin } \\
(n=12)\end{array}$ & $\begin{array}{c}\text { Non-CPB } \\
(n=6)\end{array}$ \\
\hline Age (yr) & $40 \pm 10$ & $38 \pm 11$ & $45 \pm 15$ \\
Sex (M/F) & $7 / 5$ & $8 / 4$ & $5 / 1$ \\
Pulmonary vascular disease & 3 & 4 & - \\
Obstructive lung disease & 5 & 4 & 2 \\
Restrictive lung disease & 1 & - & 3 \\
Infectious lung disease & 3 & 4 & 1 \\
\hline
\end{tabular}

the bleeding problem as a result of adverse effects such as blood-material interaction, systemic heparinization, and recirculation of wound blood that may disturb clotting and fibrinolysis in lung transplantation. ${ }^{6,7}$

Although the disturbance of clotting and fibrinolysis during cardiac operations has been widely investigated, ${ }^{8-10}$ little is known about its occurrence and prevention during lung transplantation. The antifibrinolytic agent aprotinin has been beneficial in reducing bleeding and blood transfusion in patients undergoing cardiac operations. ${ }^{11,12}$ Similarly, a beneficial effect of aprotinin might be expected during lung transplantation if similar activation of clotting and fibrinolysis occurs as during cardiac operations. Therefore we performed a prospective study to determine whether and to what extent the clotting and fibrinolytic systems were activated during lung transplantation and whether use of aprotinin in a single low-dose regimen, as during cardiac operations, was effective in inhibiting blood activation for patients undergoing lung transplantation.

\section{Patients and methods}

After approval by the local ethical committee in the University Hospital Groningen and informed consent obtained from patients, 30 lung transplantation operations performed on 29 patients were allocated into the following three study groups: group 1 , with CPB $(n=12)$; group 2, with $\mathrm{CPB}$ and $2 \times 10^{6} \mathrm{KIU}$ aprotinin administered at the beginning of CPB in the pump prime $(n=$ $12)$; and group 3 , without CPB $(n=6)$. Four unilateral and eight bilateral lung transplantations were performed in the CPB group; five unilateral and seven bilateral transplantations in the aprotinin/CPB group, and four unilateral and two bilateral transplantations in the nonCPB group. Patients' demographic data, as well as the preoperative lung disease in each group, are listed in Table I.

The donor lungs were preserved by pulmonary artery flush perfusion with a modified Euro-Collins solution of $10^{\circ} \mathrm{C}$ containing prostacyclin. After perfusion the lungs were separated from the heart and stored on sterile ice during transportation. Recipient anesthesia was per-
Table II. Duration of $C P B$, blood loss, and transfusion (mean \pm standard deviation)

\begin{tabular}{lccc}
\hline \multicolumn{1}{c}{ Parameter } & $\begin{array}{c}C P B \\
(n=12)\end{array}$ & $\begin{array}{c}\text { CPB/aprotinin } \\
(n=12)\end{array}$ & $\begin{array}{c}\text { Non-CPB } \\
(n=6)\end{array}$ \\
\hline CPB time (min) & $224 \pm 60$ & $275 \pm 68$ & - \\
Total heparin (mg) & $321 \pm 102$ & $336 \pm 60$ & - \\
Protamine (mg) & $191 \pm 44$ & $177 \pm 24$ & - \\
Blood loss (ml) & $2521 \pm 1740$ & $1991 \pm 1353$ & $875 \pm 607$ \\
RBC transfusion (unit) & $6.5 \pm 2.9$ & $7.4 \pm 3.1$ & $1.0 \pm 1.2^{*}$
\end{tabular}

$C P B$, Cardiopulmonary bypass; $R B C$, red blood cell concentrate

${ }^{*} p<0.01$ in comparison with the other two groups.

formed with a high-dose opioid-midazolam infusion technique and oxygen in air ventilation to normocapnic levels. Lung implantation was performed for unilateral and bilateral sequential procedures according to the surgical technique described by Cooper ${ }^{13}$ and Pasque and associates. $^{14}$

CPB. CPB was used for recipients from both the CPB and the aprotinin/CPB groups. The extracorporeal circuit consisted of roller pumps and a silicone sheet membrane oxygenator (SciMed Life Systems, Inc., Minneapolis, Minn.) or a microporous polypropylene membrane oxygenator (CML Excel; Cobe Laboratories, Inc., Lakewood, Colo.). The circuit was primed with human albumin and Ringer's lactate solution containing 1500 IU heparin. Before the start of CPB, systemic heparinization was achieved by intravenous administration of bovine lung heparin (300 IU/kg). During CPB, anticoagulation was maintained by additional heparin (100 IU/kg per hour) and monitored by the celite-activated clotting time (Hemochron 800, International Technidyne Corp., Edison, N.J.). Protamine hydrochloride was administered after CPB at a ratio of 1:1 to the loading dose of heparin after completion of CPB.

Laboratory measurements. For the different assays of clotting, fibrinolysis, and aprotinin activity, blood samples were taken from the indwelling radial artery catheter of the recipients at nine time points: after induction of anesthesia before the operation (T1), after the start of $\mathrm{CPB}$ but before reperfusion of the first lung (T2), 5 minutes (T3) and 30 minutes (T4) after reperfusion of the first lung, 5 minutes (T5) and 30 minutes (T6) after reperfusion of the second lung if there was a bilateral procedure, at the end of the operation (T7), and 4 hours (T8) and 24 hours (T9) after the end of the operation. Samples were anticoagulated either with $3.06 \%$ sodium citrate solution or with citrate solution containing a 100 $\mathrm{KIU} / \mathrm{ml}$ concentration of aprotinin in a blood/medium ratio of 9:1. Plasma was obtained by centrifugation of whole blood at $1000 \mathrm{~g}$ and stored at $-80^{\circ} \mathrm{C}$ for further determination.

Activation of clotting was indicated by the concentration of the thrombin-antithrombin III (TAT) complex measured in citrate-anticoagulated plasma by enzymelinked immunosorbent assay (ELISA, Behring, Marburg, Germany). Activation of fibrinolysis was indicated by fibrin degradation products (FbDP) in the citrate-aprotinin plasma by ELISA (Organon Teknika, Turnhout, Belgium). Tissue-type plasminogen activator (t-PA) concen- 


\section{TAT complex}

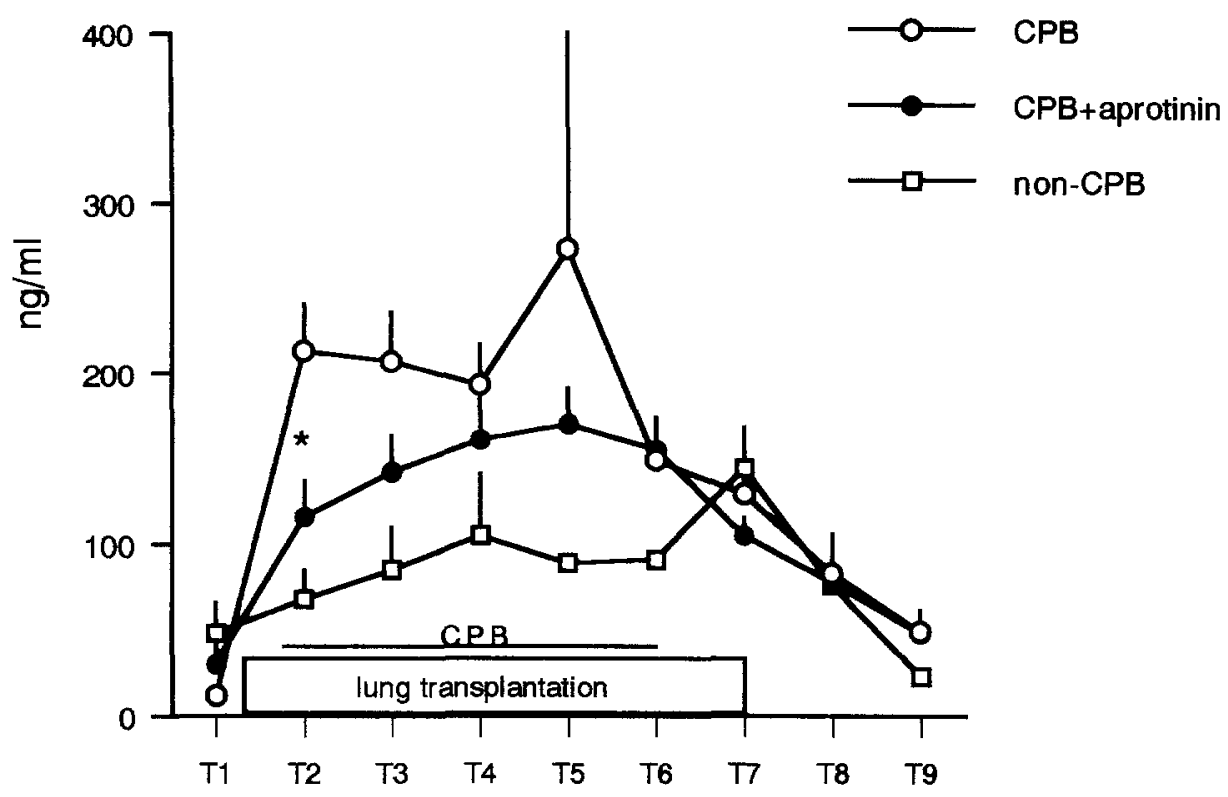

Fig. 1. Formation of TAT complex during lung transplantation in patients with $\mathrm{CPB}$, with $\mathrm{CPB}$ and aprotinin ( $C P B+$ aprotinin), and without CPB (non-CPB). Significant higher TAT was found in the CPB group than the CPB+aprotinin and the non-CPB groups $\left({ }^{*} p<0.05\right.$, comparison between groups; within-group difference, see text in Results; sample time T1 to T9, see text in Methods).

trations was determined in citrate-anticoagulated plasma by ELISA (Kabi Diagnostica, Stockholm, Sweden). Aprotinin activity was estimated by plasmin inhibiting capacity in citrated plasma samples. In brief, plasma samples were added to an excess of plasmin in buffer. Next, the residual turnover of a plasmin-specific chromogenic substrate (S2403, Chromogenix A.B., Mölndal, Sweden) was determined and measured as an increased optical density at 405 $\mathrm{nm}$ in a spectrophotometer (model 3550-UV, Bio-Rad Laboratories, Hercules, Calif.).

Clinical data. Total heparin and protamine doses used during the operation were calculated from the anesthetic records. Blood loss during the whole period of the operation was recorded according to the net weight of gauzes and the volume of the wound drainage system. Transfusion of red blood cell concentrates was decided on the basis of hemoglobin level during the operation.

Statistics. Data are expressed as mean value \pm the standard error of the mean except when stated otherwise. All the values of laboratory tests except the plasmin inhibiting capacity were corrected for hemodilution by the baseline hematocrit value before the operation (sample value $x$ baseline hematocrit/sample hematocrit). After evaluation of data distribution by the Kolmogorov-Smirnov test, either one-way analysis of variance or the Kruskal-Wallis test was applied for comparing differences among the three groups. If a significance was observed, either Student's $t$ test or the Mann-Whitney test was performed to determine the significance between each two groups. For the time-dependent difference within a group, the paired $t$ test was applied. A $p$ value less than 0.05 was considered as statistically significant.

\section{Results}

Clinical data. The mean duration of CPB was 224 minutes (107 to 300 minutes) in the CPB group and 275 minutes ( 213 to 414 minutes) in the aprotinin/CPB group. Blood loss during the operation was $2521 \pm 550 \mathrm{ml}$ in the CPB group, $1991 \pm 408 \mathrm{ml}$ in the aprotinin/CPB group, and $875 \pm 248 \mathrm{ml}$ in the non-CPB group. No statistically significant difference was observed between the groups regarding the duration of CPB and blood loss. There was also no significant difference between the CPB and the aprotinin/CPB groups in transfusion of red blood cell concentrates and fresh frozen plasma. The volume of red cell concentrates transfused was significantly lower in the non-CPB group than in the other two groups $(p<0.01)$. Total amount of heparin and protamine administered during the operation did not differ between the CPB and CPB/aprotinin groups (Table II).

TAT complex. The level of TAT complex, an indicator of clotting activation, increased significantly during the early phase of the operation in the 


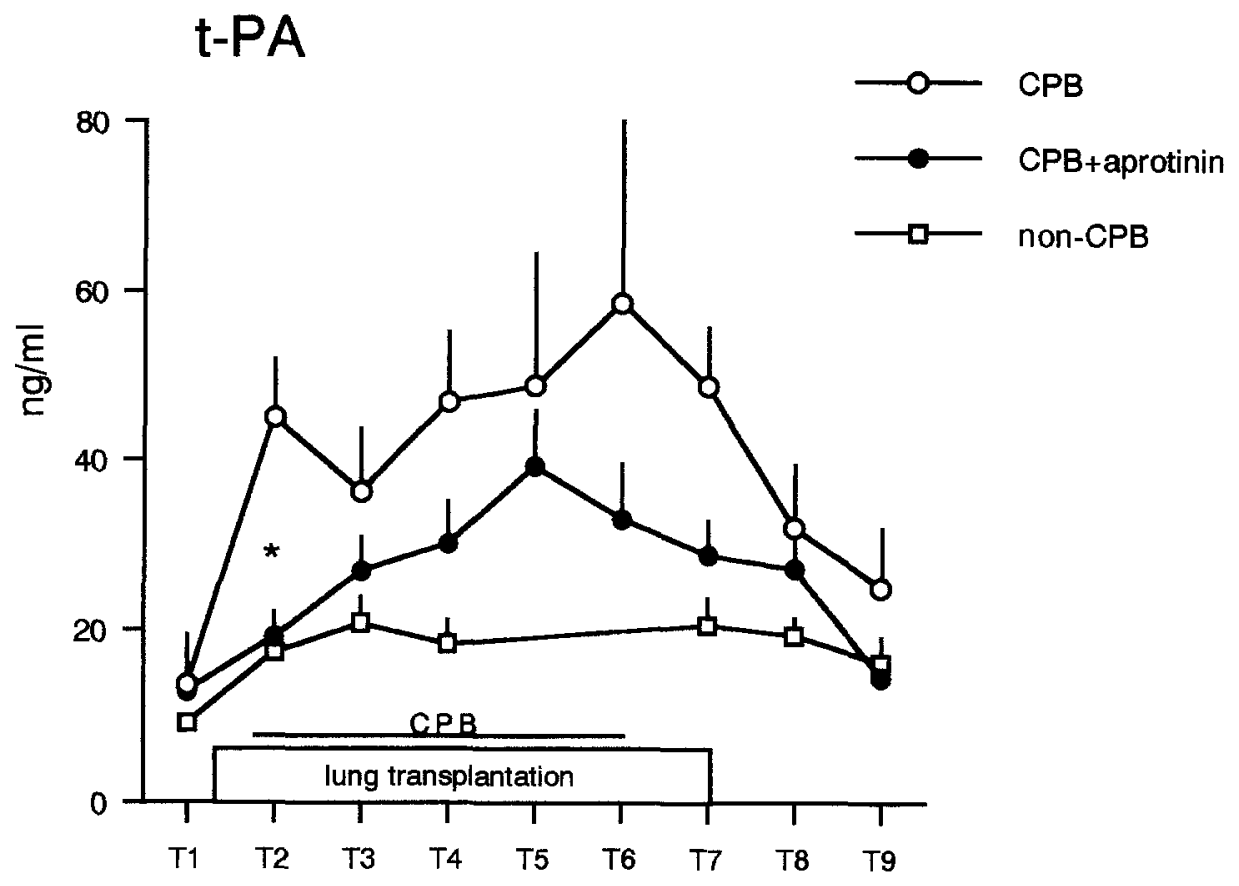

Fig. 2. t-PA release during lung transplantation in patients with $C P B$, with $C P B$ and aprotinin $\left(C P B+\right.$ aprotinin), and without $\mathrm{CPB}$ (non-CPB). $\left({ }^{*} p<0.05, \mathrm{CPB}\right.$ group versus $\mathrm{CPB}+$ aprotinin and non-CPB groups).

CPB group in comparison with its baseline concentration (from $12 \pm 2 \mathrm{ng} / \mathrm{ml}$ to $213 \pm 28 \mathrm{ng} / \mathrm{ml}, p<$ 0.01 ). High levels of TAT complex were continuously found in plasma during the late phase of the operation but declined sharply 4 hours after the operation and returned to baseline level within 24 hours. The increase of TAT complex was significantly less in the aprotinin/CPB group than in the CPB group at the initiation of CPB $(p<0.05$, Fig. $1)$, but the concentration rose progressively late during the operation and returned to the baseline level in a pattern similar to that of the CPB group. In the non-CPB group, plasma concentration of TAT also rose during the operation, but it was significantly less than the concentration in the CPB group ( $p<0.05, \mathrm{~T} 2$ to $\mathrm{T} 4$ ).

t-PA. The concentration of t-PA, a trigger of fibrinolysis released by injured endothelium, increased sharply in the early phase of the operation in the CPB group (from $13.6 \pm 5.7 \mathrm{ng} / \mathrm{ml}$ to $44.9 \pm$ $6.9 \mathrm{ng} / \mathrm{ml}, p<0.01$ ), followed by a second peak during the late phase of the operation. The t-PA concentration in plasma dropped sharply after the end of the operation and remained slightly elevated for 24 hours. In the aprotinin/CPB group, significantly less t-PA was found in circulation than in the
CPB group early during CPB ( $p<0.05$, Fig. 2$)$, but it increased later during $\mathrm{CPB}$; thus no statistically significant difference existed between the two groups. In the non-CPB group, t-PA also increased significantly during the early period of operation (T2 to T4) in comparison with the baseline concentration $(p<0.05)$, but the level was significantly lower than that in the CPB group $(p<0.05)$.

FbDP. The concentration of $\mathrm{FbDP}$, an indicator of fibrinolysis, increased significantly during the operation in the CPB group (T4 and T7 in comparison with baseline, $p<0.01$ ). However, the plasma concentration was significantly lower in the aproti$\mathrm{nin} / \mathrm{CPB}$ group at $\mathrm{T} 4(57.0 \pm 6.4 \mu \mathrm{g} / \mathrm{ml}$ vs $18.2 \pm 6.5$ $\mu \mathrm{g} / \mathrm{ml}, p<0.05$, Fig. 3). There was no increase of FbDP in the non-CPB group. Within 24 hours FbDP returned to the baseline level in all groups.

Plasmin inhibiting capacity. Plasmin inhibiting capacity reflecting aprotinin activity increased immediately after the initiation of CPB in the aproti$\operatorname{nin} / \mathrm{CPB}$ group and remained high during the early phase of the operation. Late during the operation the inhibiting capacity dropped significantly on transplantation of the second lung ( $p<0.05$, Fig. 4). In contrast to the mechanism in the aprotinin/CPB group, the plasmin inhibiting capacity dropped in 


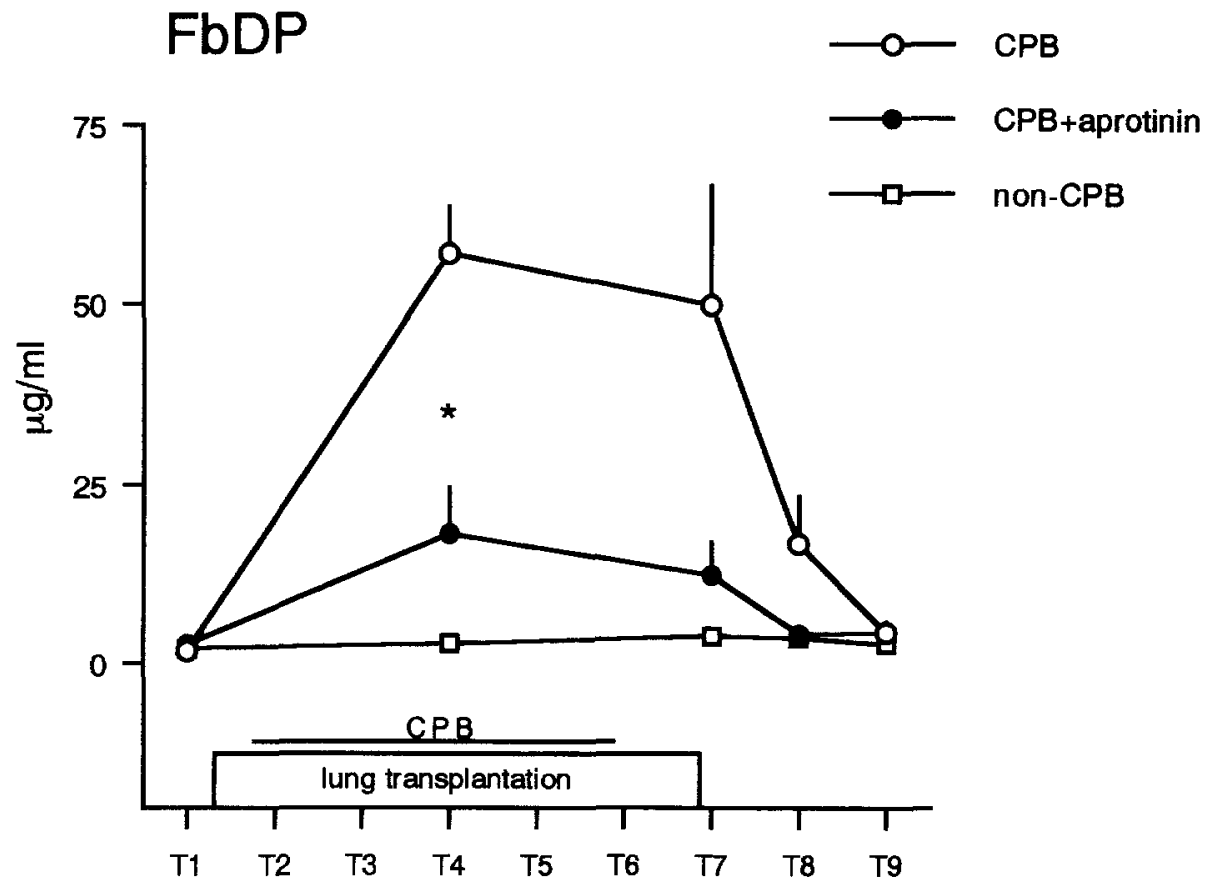

Fig. 3. FbDP production during lung transplantation in patients with $\mathrm{CPB}$, with $\mathrm{CPB}$ and aprotinin $\left(C P B+\right.$ aprotinin), and without $\mathrm{CPB}\left(\right.$ non-CPB). $\left({ }^{*} p<0.05\right.$, comparison between the CPB and the $\mathrm{CPB}+$ aprotinin groups).

the CPB group during the operation (data not corrected for hemodilution).

\section{Discussion}

Clotting appeared vigorously activated during lung transplantation and increased synergistically by $\mathrm{CPB}$, whereas excessive fibrinolysis appeared to be limited to patients requiring use of $\mathrm{CPB}$. In lung transplantation, the concentrations of TAT complex, t-PA, and FbDP were two, three, and ten times higher, respectively, than those in cardiac operations. Use of CPB is known to extensively activate clotting and fibrinolysis during cardiac operations, contributing to an acquired coagulopathy and increased bleeding tendency during and after the operations. ${ }^{8-10}$ The activation and subsequent consumption of clotting factors may result in weakness of clot formation, whereas the overstimulation of fibrinolysis may further promote clot lysis. Similarly, widespread activation of clotting and fibrinolysis during lung transplantation may have led to increased bleeding.

Previously, we ${ }^{15}$ have reported that activation of clotting during lung transplantation, as indicated by the formation of TAT complex, was about twice as high as observed during cardiac operations. In the current study, we further observed that not only the extent but also the pattern of clotting activation during lung transplantation was different from what has been observed during cardiac operations. In cardiac operations, increased TAT complex was found only in the late phase of CPB, when suction of the wound blood intensified. ${ }^{7,16}$ In lung transplantation, however, TAT complex had already increased significantly in the early phase of the operation. The early activation of the clotting system seen in patients undergoing lung transplantation could probably be explained by a larger wound area in these patients to allow surgical separation of pleural adhesion. Such a surgical trauma-induced clotting disturbance identified by the increase of TAT complex was also evident in patients undergoing lung transplantation without $\mathrm{CPB}^{15}$ and other patients having general thoracic operations. ${ }^{17}$ It has been stated recently that even during cardiac operations the major trigger of clotting activation was not the contact of blood with the foreign material (intrinsic clotting pathway), but the release of tissue factor (extrinsic clotting pathway) resulting from surgical trauma to blood vessels. ${ }^{18}$ Moreover, we ${ }^{19}$ have recently demonstrated that the retainment of thoracic wound blood during cardiac operations 


\section{Plasmin Inhibiting Capacity}

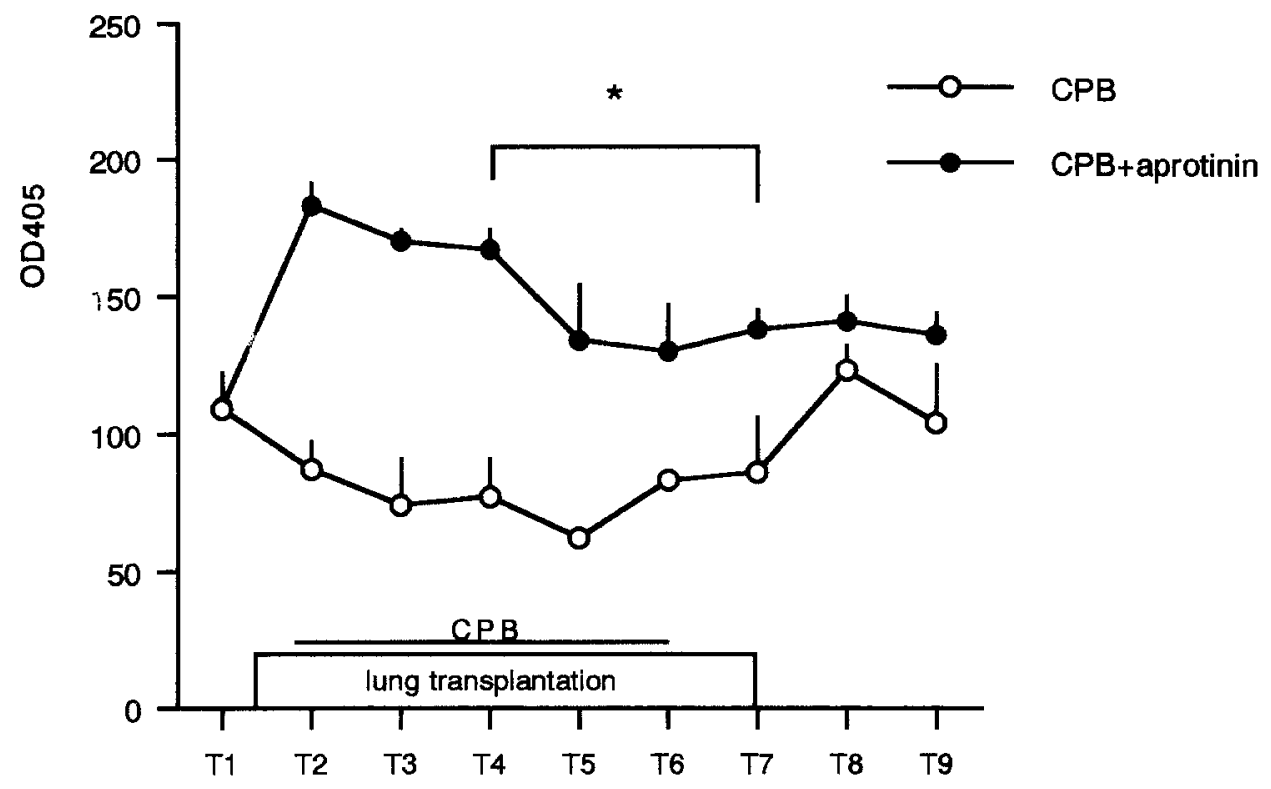

Fig. 4. Plasmin inhibiting capacity representing in part the functional aprotinin level during lung transplantation in patients with $\mathrm{CPB}$ or with $\mathrm{CPB}$ and aprotinin (CPB +aprotinin). It remained high in the aprotinin group during the early period of lung transplantation but dropped significantly afterward during the late period of the operation ( ${ }^{*} p<0.05$, within-group comparison).

resulted in significant reduction of TAT complex formation and postoperative blood loss. ${ }^{19}$ These reports support the consensus that blood-material contact in the heart-lung machine is not the mere cause leading to activation of the clotting cascade in lung transplantation.

Similar to the activation of clotting, fibrinolysis was also found to be activated both "intrinsically" and "extrinsically" during lung transplantation. The foreign material surface in the CPB circuit is known to activate fibrinolysis intrinsically through the contact activation mechanism. ${ }^{20,21}$ During lung transplantation, however, activation of fibrinolysis may also be triggered extrinsically by t-PA released from stimulated or injured endothelial cells. In the present study, a finding completely in contrast to that seen in cardiac operations was that t-PA increased sharply during the early phase of CPB (see Fig. 2), followed by a significant increase of FbDP (see Fig. 3). It is known that t-PA is the most potent activator of plasminogen that initiates fibrinolysis. ${ }^{9}$ Furthermore, t-PA together with soluble fibrin may synergistically cause platelet dysfunction, resulting in impairment of hemostasis. ${ }^{10}$
Aprotinin, a nonspecific proteinase inhibitor, was expected to be beneficial for patients undergoing lung transplantation, because it has been demonstrated to reduce nonsurgical bleeding in patients undergoing cardiac operations with CPB. ${ }^{11,12}$ During cardiac operations, a low-dose regimen $\left(2 \times 10^{6}\right.$ KIU) administered in the pump priming solution has been as effective as the high-dose infusion $(6 \times$ $10^{6} \mathrm{KIU}$ ) in terms of inhibiting the CPB-induced blood activation and blood saving. ${ }^{22,23}$ Furthermore, low-dose aprotinin treatment is considered less likely to induce postoperative renal damage. ${ }^{24}$ As observed in this study of patients having lung transplantation, fibrinolysis was sufficiently inhibited during the initial phase of the operation by a low dose of aprotinin as identified by increased plasmin inhibiting capacity (see Fig. 4). However, late during the operation the inhibiting effect of aprotinin was reduced, with a significant drop of plasmin inhibiting capacity in plasma. Because in this study patients receiving aprotinin had received no less heparin than patients not receiving aprotinin, it is less likely that the reduction of plasmin inhibiting capacity at the late period of operation was due to a reduced 
anticoagulation. It thus seems that the low-dose regimen of aprotinin administered in the pump priming solution for patients having lung transplantation inhibits fibrinolysis only during the early phase but not during the whole period of the operation because of massive activation of fibrinolysis. Therefore a maintaining dose at least during the late period of lung transplantation must be considered in case the patient needs to receive aprotinin.

An obvious limitation of this study was that these patients were not randomized to receive aprotinin. From the clinical point of view, patients in the aprotinin-treated group are those who were considered to be at high risk for bleeding and postoperative morbidity. However, no greater blood activation and blood loss was observed in these patients than in those who underwent $\mathrm{CPB}$ without receiving aprotinin, which suggests that patients at high risk for bleeding benefited from aprotinin administration. This observation is in agreement with results of a recent nonrandomized retrospective study by Jaquiss, Huddleston, and Spray, ${ }^{25}$ which indicated that aprotinin reduced intraoperative blood loss and transfusion requirements in a group of pediatric patients undergoing lung transplantation procedures. In addition, the beneficial effect of aprotinin was also reported recently by Kesten and cowork$\mathrm{ers}^{26}$ in sequential single-lung transplant patients undergoing CPB.

We conclude from this study that clotting and fibrinolysis are activated during lung transplantation, particularly in the early phase of the operation. The observed disturbance of clotting and fibrinolysis during lung transplantation is caused by a combined effect of surgical trauma and CPB. Aprotinin administration in a dose of $2 \times 10^{6} \mathrm{KIU}$ in the pump prime significantly reduced the disturbance of clotting and fibrinolysis during the early phase of lung transplantation but did not last for the whole period of the operation. Further investigation may focus on a dose-response relationship between aprotinin and the suppression of clotting and fibrinolytic activation in patients undergoing lung transplantation.

\section{REFERENCES}

1. Griffith BP, Hardesty RL, Armitage JM, Hattler BG, Pham SM, Keenan RJ, et al. A decade of lung transplantation. Ann Surg 1993;218:310-20.

2. Gayes JM, Giron L, Nissen MD, Plut D. Anesthetic consid- erations for patients undergoing double-lung transplantation. J Cardiothorac Anesth 1990;4:486-98.

3. Raffin L, Michel-Cherqui M, Sperandio M, Bonnette P, Bisson A, Loirat $\mathrm{P}$, et al. Anesthesia for bilateral lung transplantation without cardiopulmonary bypass: initial experience and review of intraoperative problems. J Cardiothorac Vasc Anesth 1992;6:409-17.

4. Patterson GA, Cooper JD, Goldman B, Weisel RD, Pearson FG, Waters PF, et al. Technique of successful clinical doublelung transplantation. Ann Thorac Surg 1988;45:626-33.

5. Triantafillou AN, Pasque MK, Huddleston CB, Pond CG, Cerza RF, Forstot RM, et al. Predictors, frequency, and indications for cardiopulmonary bypass during lung transplantation for adults. Ann Thorac Surg 1994;57:1248-51.

6. van Oeveren W. Leukocyte and platelet activation during extracorporeal circulation. Cells Materials 1994;4:187-95

7. de Haan J, Boonstra PW, Tabuchi N, van Oeveren W, Ebels T. Retransfusion of thoracic wound blood during heart surgery obscures biocompatibility of the extracorporeal circuit. J Thorac Cardiovasc Surg 1996;111:272-5.

8. Stibbe J, Kluft C, Brommer EJP, Gomes M, de Jong DS, Nauta J. Enhanced fibrinolytic activity during cardiopulmonary bypass in open-heart surgery in man is caused by extrinsic (tissue-type) plasminogen activator. Eur $\mathrm{J}$ Clin Invest 1984;14:375-82.

9. Tanaka K, Takao M, Yada I, Tuasa H, Kusagawa M, Deguchi $\mathrm{K}$. Alterations in coagulation and fibrinolysis associated with cardiopulmonary bypass during open heart surgery. J Cardiothorac Anesth 1989;3:181-8.

10. de Haan J, Schönberger J, Haan J, van Oeveren W, Eijgelaar A. Tissue-type plasminogen activator and fibrin monomers synergistically cause platelet dysfunction during retransfusion of shed blood after cardiopulmonary bypass. J Thorac Cardiovasc Surg 1993;106:1017-23.

11. van Oeveren W, Jansen NJG, Bidstrup BP, Royston D, Westaby S, Neuhof H, et al. Effects of aprotinin on hemostatic mechanisms during cardiopulmonary bypass. Ann Thorac Surg 1987;44:640-5.

12. Bidstrup BP, Royston D, Sapsford RN, Taylor KM. Reduction in blood loss and blood use after cardiopulmonary bypass with high-dose aprotinin (Trasylol). J Thorac Cardiovasc Surg 1989;97:364-72.

13. Cooper JD. The evolution of techniques and indications for lung transplantation. Ann Surg 1990;212:249-56.

14. Pasque MK, Cooper JD, Kaiser LA, Haydock DA, Triantafillou A, Trulock EP. Improved technique for bilateral lung transplantation: rationale and initial clinical experience. Ann Thorac Surg 1990;49:785-91.

15. Gu YJ, van Oeveren W, Boonstra PW, de Boer WJ, Ebels T, Prop J. Heparin-coated cardiopulmonary bypass circuit for use during lung transplantation. J Heart Lung Transplant 1995;14:605-6.

16. Tabuchi $\mathrm{N}$, de Haan J, Boonstra PW, van Oeveren W. Activation of fibrinolysis in the pericardial cavity during cardiopulmonary bypass. J Thorac Cardiovasc Surg 1993;106: 828-33.

17. Onizuka M, Miyauchi T, Mitsui K, Suzuki N, Ueno H, Gogo $\mathrm{K}$, et al. Plasma levels of endothelin-1 and thrombin-antithrombin III complex in patients undergoing open chest operations [letter]. J Thorac Cardiovasc Surg 1993;105:55960. 
18. Boisclair MD, Lane DA, Philippou H, Esnouf MP, Sheikh S, Hunt $B$, et al. Mechanism of thrombin generation during surgery and cardiopulmonary bypass. Blood 1993;82: 3350-7.

19. de Haan J, Boonstra PW, Monnink S, Ebels T, van Oeveren W. Retransfusion of thoracic wound blood during cardiopulmonary bypass impairs hemostasis. Ann Thorac Surg 1995; 59:901-7.

20. Colman RW. Surface-mediated defense reactions: the plasma contact activation system. J Clin Invest 1984;73:1249-53.

21. Wachtfogel YT, Harpel PC, Edmunds LH Jr, Colman RW. Formation of C1s-C1-inhibitor, kallikrein-C1-inhibitor, and plasmin-a2-plasmin-inhibitor complexes during cardiopulmonary bypass. Blood 1989;73:468-71.

22. van Oeveren W, Harder MP, Roozendaal KJ, Eijsman L, Wildevuur CRH. Aprotinin protects platelets against the initial effect of cardiopulmonary bypass. J Thorac Cardiovasc Surg 1990;99:788-97.

23. Schönberger JPAM, Everts PAM, Ercan H, Bredée JJ, Bavinck JH, Berreklouw E, et al. Low-dose aprotinin in internal mammary artery bypass operations contributes to important blood saving. Ann Thorac Surg 1992;54:1172-6.

24. Feindt PR, Walcher S, Volkmer I, Keller HE, Straub LI, Huwer H, et al. Effect of high-dose aprotinin on renal function in aortocoronary bypass grafting. Ann Thorac Surg 1995;60:1076-80.

25. Jaquiss RDB, Huddleston CB, Spray TL. Use of aprotinin in pediatric lung transplantation. J Heart Lung Transplant 1995;14:302-7.

26. Kesten S, de Hoyas A, Chaparro C, Westney G, Winton T, Maurer JR. Aprotinin reduces blood loss in lung transplant recipients. Ann Thorac Surg 1995;59:877-9.

\section{Availability of Journal back issues}

As a service to our subscribers, copies of back issues of The Journal of Thoracic and Cardiovascular Surgery for the preceding 5 years are maintained and are available for purchase from Mosby at a cost of $\$ 13.50$ per issue until inventory is depleted. The following quantity discounts are available: $25 \%$ off on quantities of 12 to 23 , and one third off on quantities of 24 or more. Please write to Mosby-Year Book, Inc., Subscription Services, 11830 Westline Industrial Drive, St. Louis MO 63146-3318, or call 800-453-4351 or 314-453-4351 for information on availability of particular issues. If unavailable from the publisher, photocopies of complete issues may be purchased from UMI, 300 N. Zeeb Rd., Ann Arbor, MI 48106, 313-761-4700. 